\title{
Traumatic Pseudoaneurysm of Subscapulr Artery- A Case Report
}

\author{
Dr. Vivek Rawat ${ }^{1}$ M.S,Dr Shaikh Mohammed Husain ${ }^{2}$ Dnb General \\ Surgery,Dr. Rajkumar Yadav ${ }^{3}$ M.Ch. \\ ${ }^{1,2,3}$ Department of Cardiovascular \& Thoracic Surgery, SMS Medical College \& Hospital, Jaipur, \\ Rajasthan (India)
}

\begin{abstract}
Traumatic pseudoaneurysm of subscapular artery is a rare sequlae of injury in the shoulder region. Only five cases are on report and none after World War II. This rarity of the lesion is due to the anatomic location of the artery. We report a 21 years old patient transferred for torrential bleeding from the wound of entry, followed by appearance of progressively expanding, pulsatile, painful swelling, after three days of splinter injury sustained in right scapular region while working in the field. The diagnosis was confirmed by Doppler ultrasonography and computerized tomographic angiography.

Successful surgical aneurysmectomy and ligation of rented subscapular artery done without affecting axillary artery.
\end{abstract}

Keywords: Pseudoaneurysm, subscuplar artery, penetrating injury

\section{Introduction}

The subscapular artery is the largest branch of third part of axillary artery lies on the subscapularis muscle in close association with the chest wall medially ${ }^{4}$. It branches off backward in Scapular Circumflex and Thoracodorsal artery approximately $4 \mathrm{~cm}$ from the origin. The pseudoaneurysm of subscapular artery develops after penetrating trauma around the shoulder. Only five cases so far found reported in the literature by Liston ${ }^{1}$, $\mathrm{McGraw}^{2}$, Makins ${ }^{3}$ and Robert ${ }^{4}$ No case report could be traced in the literature after World War II. The rarity of the lesion is due to the anatomic location of the artery ${ }^{4}$. A perforation of the artery in the distal two-third of its course would probably close spontaneously because the small fascial space would limit expansion of a blood clot, while in the proximal third, near its origin, associated perforation of the axillary artery would be likely ${ }^{4}$.

\section{Case Report}

A 21 years old patient transferred to our tertiary level hospital after 3 days of splinter injury sustained posteriorly in scapular region while he was working in the farm. There was history of torrential bleeding from the wound of entry, followed by appearance of painful swelling. On examination - there was an entry wound posteriorly just lateral to outer boarder of left scapula. There was a swelling underneath measuring $6 \times 5 \mathrm{~cm}$ present in between left posterior axillary fold and rib cage which was tender and pulsatile. There was no wound of exit. The left radial pulse was palpable and equal to contralateral side. There was no neurological deficit in the concerned upper limb. Patient was pale, hemoglobin was $7.0 \mathrm{gm} \%$, haematocrit was $22 \%$, and blood pressure was 130/70 $\mathrm{mm} \mathrm{Hg}$. The rest of the investigations and physical examinations were unremarkable.

$\mathrm{X}$-ray left shoulder region was done which showed fracture of scapula lower part and hyperdense opacity in vicinity? metallic foreign body.

USG chest revealed a well defined cystic lesion of size $35 \times 33 \mathrm{~mm}$ seen in the left upper back showing prominent vascularity, feeding vessel and yin-yang sign on doppler suggesting turbulent flow likely due to pseudo aneurysm formation.

CT Angiography was then done which showed a well defined rounded saccular contrast extravasations noted arising from sub scapular artery (Fig.) measuring $25 \times 28 \times 46 \mathrm{~mm}$ suggestive of pseudoaneurysm, large hematoma is noted in the surrounding region.

\section{Surgical Procedure}

The patient was taken for surgical intervention. Exploration was started by extending the entry wound towards axilla up to anterior axillary fold. Axillary artery identified, it was found normal throughout. On further exploration there was a large pseudoaneurysm from subscapular artery quite away from its origin from axillary artery. After proximal and distal control of axillary artery, aneurysm opened all clots removed there was a large tear in distal subscapular artery. Ligation of subscapular artery proximal and distal to the rent done. Foreign body could not be retrieved. Homeostasis achieved, incision closed in layers. Post operative period was uneventful. 


\section{Discussion}

Upper extremity pseudoaneurysm encountered very less frequently than in lower extremities ${ }^{5}$. Infection, polyarteritis nodosa, congenital arterial defects, and especially trauma play a role in the pathogenesis of upper extremity pseudoaneurysms. If the only causal factor is trauma, the aneurysm takes the form of a pseudoaneurysm ${ }^{5}$. Pseudoaneurysm mostly occur due to penetrating injury, may sometimes due to blunt trauma specially $3^{\text {rd }}$ part of axillary artery and its branches e.g. subscapular artery as these are relatively fixed structures ${ }^{5}$. The usual presentation is growing mass at or near the site of trauma which is pulsatile, warm and fixed. The sub scapular artery pseudoaneurysm is very rare only few cases are on report before World War II. No such case could be traced in the literature after the World War II. This rarity of the lesion is due to the anatomic location of the artery ${ }^{5}$ and may be because the small fascial space that would limit expansion of a blood $\operatorname{clot}^{4}$ especially in distal two third of its course. Contrary to it, in our case rent was present in distal part of subscapular artery.

The option of management of such pseudoanerysm are surgery or catheter based endovascular coiling or embolisation. The choice of procedure to be adopted depends upon facilities available, expertise of the surgeon or endovascular specialist. Surgery is gold standard and cheap but it has a higher operative and postoperative complication rate and is more difficult when the aneurysm has ruptured ${ }^{7}$ and long standing.

In this particular case we did surgical intervention by ligating the subscapular artery proximal and distal to the rent in distal part. The sac was excised without any impairment in the axillary artery continuity and flow or any other complication.

Endovascular treatment or surgery or both in combination have been described. An endovascular approach is the best therapeutic alternative, since it can be combined with revascularization of the causative occlusion or stenosis if exist. The procedure also depends on the need to preserve the aneurysmal artery flow ${ }^{6}$.

\section{Abbreviations:}

USG : Ultra Sonography, CT : Computerised Tomography

\section{Figures}

(Fig.1) X-ray of left shoulder showing metallic foreign body and fracture of lower part of scapula (angle).

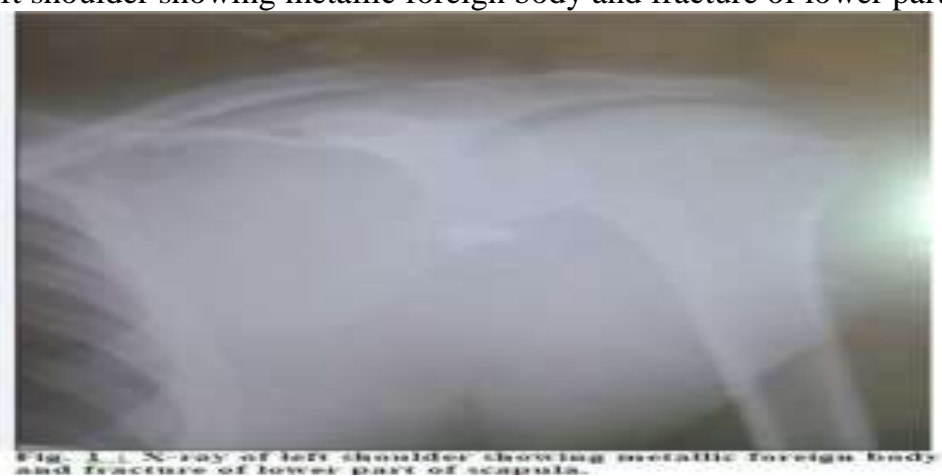

(Fig.2) CT angiogram of left upper limb showing pseudo aneurism arising from subscuplar artery, metallic foreign body is also seen 


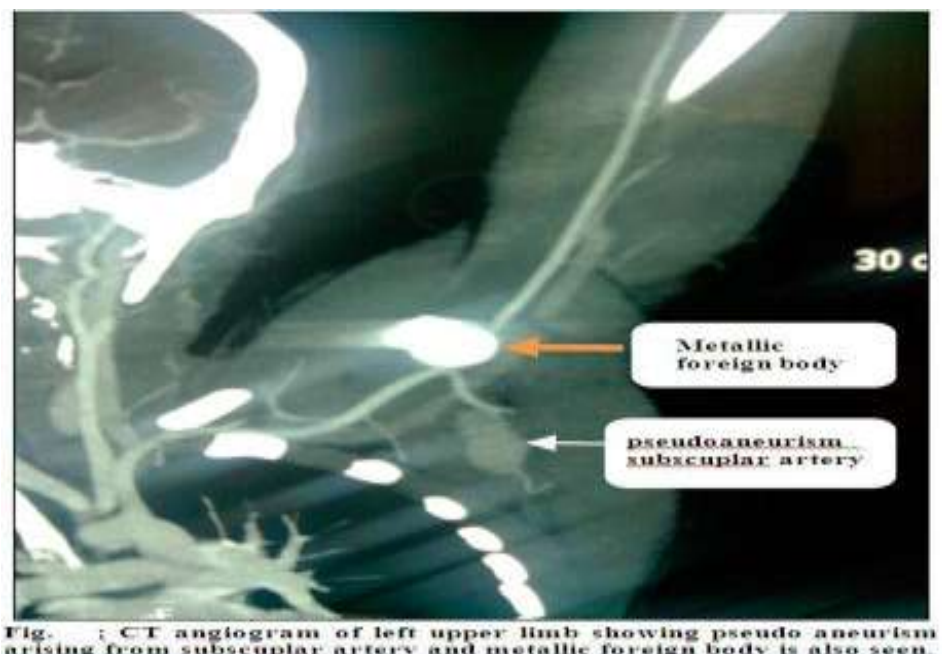

(Fig.3) Postoperative photograph showing incision started from the wound of entry posteriorly and extended across the axilla upto anterior axillary fold.

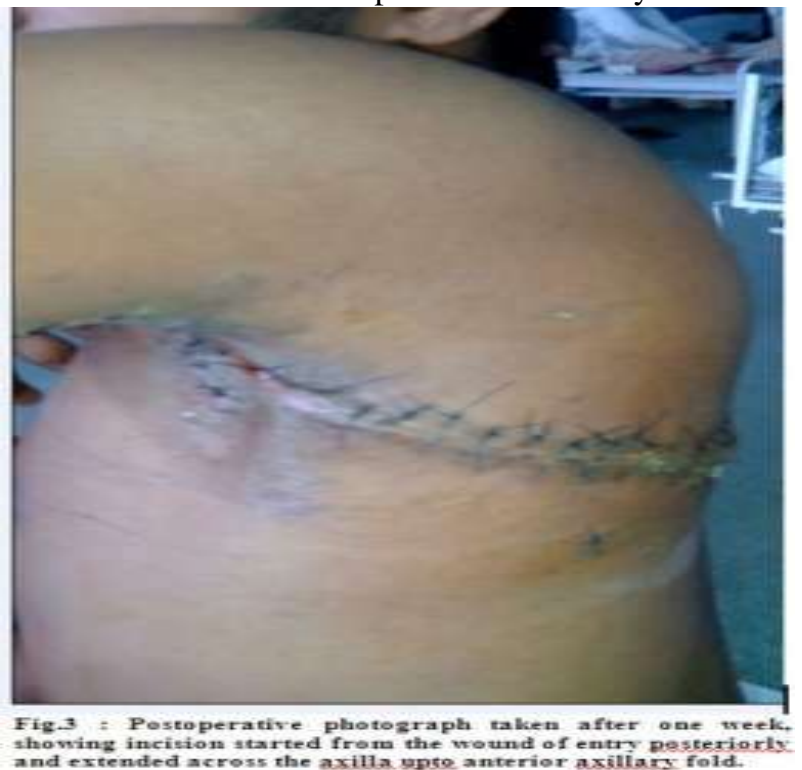

\section{References}

[1]. Liston, R. : Ossified Aneurysmal Tumour of the Subscapular Artery. Edinburgh Med. \& Surg. J., $16: 66,215,1820$

[2]. McGraw, T.A. : A Case of Traumatic Aneurysm of the Subscapular Artery. New York Med. J., 41 : 569, 1885.

[3]. Makins, George H. : Gunshot Injuries of the Blood Vessels, Bristol, John Wright \& Sons, Ltd., 1919.

[4]. Robert A. Wise, Traumatic Aneurysm of the Subscapular Artery, Vol. 127, Number 3, Annals of Surgery, March 1958, pg. 569571.

[5]. B. Dympep, S. Khangarot \& N. Hadke, An unusual presentation of traumatic pseudoaneurysm of axillary artery mimicking soft tissue tumor, JSCR 2012 10:17, Pg1-4.

[6]. Antoine Moreau, Julien Joskin, Julie Kreutz and Alain Nchimi, Ruptured subscapular artery aneurysm and subclavian artery occlusion in a patient with type 1 neurofibromatosis: a case report Journal of Medical Case Reports 2014, 8:39 doi:10.1186/17521947-8-39

[7]. $\quad 7$.Flood K, Nicholson AA : Inferior pancreaticoduodenal artery aneurysms associated

[8]. with occlusive lesions of the celiac axis: diagnosis, treatment options, outcomes, and

[9]. review of the literature. Cardiovasc Intervent Radiol 2013, 36:578-587. Pubmed abstract

[10]. Publisher Full Text 